\title{
A DIMENSÃO ÉTICA DA PSICOLOGIA ANALÍTICA: INDIVIDUAÇÃO COMO "REALIZAÇÃO MORAL"
}

\author{
Marco Heleno Barreto*
}

\section{RESUMO}

$\mathrm{O}$ artigo expõe a centralidade da dimensão ética inerente à Psicologia Analítica de Carl Gustav Jung através de uma minuciosa referência a passagens fundamentais do texto junguiano, frequentemente não percebidas na importância que têm para uma correta compreensão da natureza da praxis psicoterapêutica formulada por Jung. O autor sustenta ainda que a (in)atualidade da clínica junguiana no cenário contemporâneo deve ser pensada à luz da (in)compatibilidade entre esta dimensão ética específica e as tendências que organizam hoje o modo humano de ser-no-mundo.

Palavras-chave: Jung; psicologia analítica; individuação; ética.

\section{Abstract}

THE ETHICAL DIMENSION OF ANALYTICAL PSYCHOLOGY: INDIVIDUATION AS "MORAL ACHIEVEMENT"

The article exposes the centrality of the ethical dimension in Carl Gustav Jung's Analytical Psychology, through a careful reference to fundamental moments in the Jungian text, which are often ignored as to the importance they have to a correct understanding of the nature of the psychotherapeutic praxis proposed by Jung. The author also claims that the validity of Jungian clinics nowadays must be thought in the light of the (in)compatibility between this specific ethical dimension and the major trends which mold today the human way of being-in-theworld.

Keywords: Jung; analytical psychology; individuation; ethics.

* Psicólogo Analista e Professor Adjunto da Faculdade Jesuíta de Filosofia e Teologia (FAJE) de Belo Horizonte. 
Quem percorre a diversificada casuística clínica presente na obra de Carl Gustav Jung depara-se com a história, narrada em três passagens diferentes (Jung, [1934] 1969 [CW 8], \$ 685; [1946] 1954 [CW 17], \$\$ 182-183; [1935b] 1980 [CW 18], $\$ \$ 282,284)^{1}$, de um homem de 30 anos, descrito por Jung como sendo altamente inteligente e intelectualizado, que o procura trazendo uma monografia acerca de sua neurose compulsiva, que ele próprio elaborara rigorosamente, uma espécie de autobiografia psicanalítica de alto nível, testemunhando uma admirável compreensão psicológica a respeito de seu estado psicopatológico. O homem quer saber o motivo pelo qual, após uma compreensão tão aprofundada dos mecanismos neuróticos que o aprisionavam, ele continua neurótico. Jung lê com admiração o excelente e volumoso manuscrito, considerando-o mesmo apto a publicação, e não vê falhas na compreensão intelectual ali desenvolvida, também não entendendo o por quê de a neurose não ter desaparecido. Faz, então, a anamnese do jovem autor, e vem à tona um fato singular: ele mantinha uma relação amorosa com uma mulher um pouco mais velha que ele, uma professora que vivia com os modestos recursos de seu trabalho e que financiava as férias de seu amante em Saint Moritz e Nice, passando mesmo por privaçôes para sustentar o lazer daquele com quem sonhava casar - sem ser nem mesmo remotamente correspondida. Jung afirma então que a falta de consciência moral era a causa da neurose, e por tal motivo a compreensão intelectual de nada servira em termos terapêuticos. Comunica sua posição ao jovem, que a considera chocantemente não-científica, uma vez que a moral nada tem a ver com a ciência, e retira-se indignado com o que desqualifica como sendo uma postura moralista de Jung, não sem antes contestar que o assunto já fora discutido com sua amante, e que ambos não atribuíam importância àquela circunstância.

Refletindo sobre tal caso a partir do ponto de vista terapêutico, Jung afirma que aquele jovem "era um dos muitos que acreditam que a moral não tem nada a ver com a neurose, e que pecar intencionalmente não é de forma alguma pecar, porque o pecado pode ser intelectualmente anulado" (Jung, [1946] 1954 [CW 17], $\$ 182$ ), declarando logo após que acredita "firmemente no poder e dignidade do intelecto, mas somente se ele não violar os valores do sentimento” (Jung, [1946] 1954 [CW 17], $\$ 183)^{2}$, e assim considera que "a atitude moral é um fator real que o psicólogo deve levar em consideração, se não quiser cometer os mais graves erros" (Jung, [1934] 1969 [CW 8], \$ 686). Jung afirma, pensando na condição de possibilidade para que o tratamento desse jovem tivesse alguma chance de sucesso, que seria necessário começar enfocando "a base impossível de sua vida" (Jung, [1946] 1954 [CW 17], \$183). 
Esta anedota clínica pode parecer isolada e dizer respeito tão-somente a um aspecto dentre outros na perspectiva psicoterapêutica criada por Jung, por exemplo ao assim chamado confronto com a sombra, entendida em sentido restrito ${ }^{3}$. Mas, se rastrearmos atentamente o texto junguiano, perceberemos que não é assim. O "fator moral" enraíza-se no centro mesmo da concepção psicológica e terapêutica de Jung, e não seria exagerado afirmar que ele constitui na verdade um de seus fundamentos irrenunciáveis. No atual clima civilizacional, marcado por uma crise ética sem precedentes, que apresenta suas credenciais sob a forma do relativismo moral dominante, e que molda o espaço humano de maneira indelével, pensar a atualidade - ou inatualidade - da clínica junguiana exige que nos detenhamos para refletir sobre a dimensão ética da psicologia analítica.

No que diz respeito à perspectiva psicoterapêutica que Jung funda a partir de sua experiência de "crise criativa", vivida após a ruptura com Freud, a confirmação do primado do ético pode ser encontrada em suas Memórias, recolhidas e editadas por Aniela Jaffé (1982). O essencial daquela experiência fundadora está registrado no capítulo "Confronto com o Inconsciente", juntamente com reflexões de alcance geral, que especificam os traços exemplares ou prototípicos daquele confronto, e portanto da praxis psicoterapêutica a ele referida. A dada altura, Jung comenta:

Mesmo aquele que adquire uma certa compreensão das imagens do inconsciente, acreditando porém que é suficiente ater-se a tal saber, torna-se vítima de um erro perigoso. Pois quem não sente a responsabilidade ética que seus conhecimentos comportam sucumbirá ao princípio de poder. Disso poderão resultar efeitos destruidores não só para os outros como também para a própria pessoa que sabe. As imagens do inconsciente impõem ao homem uma pesada obrigação. Sua incompreensão, assim como a falta de sentido da responsabilidade ética, privam a existência de sua totalidade e conferem a muitas vidas individuais um cunho de penosa fragmentação (Jaffé, 1982: 171).

Por outro lado, sabemos que um momento fundamental do confronto com o inconsciente em Jung consistiu na elaboração estética de suas fantasias e imagens, registradas no conhecido Livro vermelho, sendo esta uma das ferramentas privilegiadas do método da imaginação ativa, que ele desenvolve no calor mesmo do embate com o inconsciente. Porém, assim como acontece com a compreensão intelectual, também a elaboração estética deve subordinar-se à dimensão ética, conforme Jung: 
A elaboração estética do Livro vermelho foi-me necessária, por maior que tenha sido a irritação que às vezes me causou; através dela cheguei à compreensão da responsabilidade ética em relação às imagens. Esta atitude influenciou a conduta de minha vida de modo decisivo. Compreendi que nenhuma [linguagem], por mais perfeita que seja, pode substituir a vida. Se procurar fazê-lo, não somente ela se deteriorará, como também a vida. Para conseguir a liberação da tirania dos condicionamentos do inconsciente duas coisas são necessárias: desincumbirmo-nos de nossas responsabilidades intelectuais e também de nossas responsabilidades éticas (Jaffé, 1982: 167).

Jung alerta para o risco de um certo esteticismo, que ele atribui à influência sugestiva da anima, sempre dando prioridade à atitude moral:

Se eu tivesse [tomado] as fantasias do inconsciente por manifestações artísticas, tê-las-ia contemplado com meu olho interior ou deixado que elas se desenrolassem como um filme. Não seriam mais convincentes do que qualquer percepção dos sentidos e, por outro lado, não teriam despertado em mim qualquer vestígio de dever moral (Jaffé, 1982: 166) ${ }^{4}$.

Fica evidente, portanto, que o envolvimento moral nas experiências que constituem o confronto com o inconsciente ocupa o primeiro plano na concepção terapêutica de Jung, a tal ponto que ele define a cura da neurose como uma realização mora $\bar{T}$. Sempre apontando para a possibilidade de uma dissociação entre o conhecimento intelectual e o compromisso ético que ele traz consigo, Jung condiciona inquestionavelmente a cura da neurose à atitude moral correspondente, vendo nisso o critério de legitimidade da experiência do inconsciente:

Dado que o homem civilizado possui um grau de dissociabilidade muito elevado e dele se utiliza continuamente a fim de evitar qualquer possibilidade de risco, não é garantido que o conhecimento seja acompanhado da ação correspondente. Pelo contrário, devemos contar com a extrema ineficácia do conhecimento e insistir por isso numa aplicação significativa do mesmo. $\mathrm{O}$ conhecimento por si mesmo não basta, nem implica alguma força moral. Nestes casos vemos claramente como a cura da neurose é um problema moral (Jung, [1954] 1968 [CW 9-i], \$ 84).

Wolfgang Giegerich (1999), talvez o mais consequente crítico de Jung na atualidade, sustenta - acertadamente - que o autêntico conhecimento intelectual é simultânea e indissoluvelmente uma "realização moral", apesar de não 
usar esta expressão. A possibilidade de dissociação aventada por Jung, nessa perspectiva, corresponde a uma forma de defesa, que mantém a dissociação neurótica e que poderíamos classificar como racionalização, um simulacro que distorce e deturpa a genuína compreensão intelectual, assim como o esteticismo também deturparia o genuíno envolvimento estético. De qualquer modo, persiste a exigência da presença da atitude moral efetiva como critério de cura. Sem a "função moral", que Jung define como "lealdade a si mesmo", a posição neurótica não pode ser ultrapassada ${ }^{6}$.

Mas, devemos perguntar, o que concretamente significa tudo isso? Seria a análise, então, uma forma velada ou explícita de aconselhamento moral? A anedota clínica do homem que explorava a professora apaixonada poderia nos levar a aceitar essa hipótese - afinal, infere-se que Jung limitou-se a confrontar o jovem com a imoralidade de sua posição. Mas, por baixo dessa intervenção clínica, não devemos perder de vista o rápido comentário de Jung a respeito da "base impossível da vida" daquele homem, verdadeira raiz de sua neurose. Em que sentido a atitude do jovem assentar-se-ia em uma "base impossível de vida"?

Certamente, não pelo simples fato de colidir com a moralidade coletiva. Em uma passagem em que aborda a questão da integração dos conteúdos do assim chamado "inconsciente pessoal", e que tem um inequívoco caráter aforístico com respeito à relação com o inconsciente em geral, Jung diz que a perda de tais conteúdos inconscientes, integrantes da personalidade, produz na consciência uma inferioridade moral, sinal de que deveríamos nos esforçar para conscientizálos, e conclui:

O sentimento de inferioridade moral não provém de uma colisão com a lei moral geralmente aceita e de certo modo arbitrária, mas de um conflito com o próprio si-mesmo (Selbst) que, por razões de equilíbrio psíquico, exige que o déficit seja compensado. Sempre que se manifesta um sentimento de inferioridade moral, aparece a necessidade de assimilar uma parte inconsciente e também a possibilidade de fazê-lo. Afinal, são as qualidades morais de um ser humano que o obrigam a assimilar seu si-mesmo inconsciente, mantendo-se consciente, quer pelo reconhecimento da necessidade de fazê-lo, quer indiretamente, através de uma penosa neurose. Quem progredir no caminho da realização do si-mesmo inconsciente trará inevitavelmente à consciência conteúdos do inconsciente pessoal, ampliando o âmbito de sua personalidade. Poderia acrescentar que esta "ampliação" se refere, em primeiro lugar, à consciência moral, ao autoconhecimento, pois os conteúdos do inconsciente liberados e conscientizados pela análise são em geral desagradáveis e por isso mesmo foram reprimidos (Jung, [1935a] 1966 [CW 7], \$218). 
Tomando esta posição em seu alcance ampliado, extensivo via de regra a toda situação envolvendo a tomada de consciência de quaisquer fatores inconscientes, como fica claro pelas observações de Jung nas Memórias, podemos referendar com segurança a afirmação de que "consciência moral e autoconhecimento estão no fundamento de tudo aquilo que se manifestará na análise" (Pieri, 2002: 463). Lembrando que para Jung o autoconhecimento "nada tem a ver com o conhecimento subjetivo que o ego tem de si", e que é "um estudo difícil e moralmente exigente” (Jung, [1951] 1968 [CW 9-ii], \$ 251)7, podemos então perceber como a primazia do "fator moral" segundo Jung está indissoluvelmente vinculada às duas noções básicas em torno das quais se organiza o campo psicoterapêutico na psicologia analítica: as noçōes mutuamente remitentes de individuação e de $S i$ mesmo. Se definirmos a individuação como a realização do Si mesmo, em suas múltiplas instâncias - o que implica entendermos o Si mesmo no sentido lato, como a totalidade da psique -, então é perante tal realização que se impõe o "dever moral" a que Jung se refere, e é por isso que ela é uma realização moral.

Portanto, para além do âmbito circunscrito da cura de neuroses, é o próprio processo de individuação que se afigura como uma realização moral na perspectiva de Jung. Por isso, a razão mais profunda da neurose compulsiva da anedota clínica que destacamos estaria na incompatibilidade entre a atitude do sujeito e o impulso de individuação; assim, o tal jovem mantinha-se neuroticamente numa posição infantil irrealista, já não mais condizente com a sua realidade, que lhe impunha a responsabilidade adulta por sua própria vida.

No caso desse jovem explorador da professora, a "lealdade a si mesmo" coincide com a "lei moral geralmente aceita e de certo modo arbitrária". Mas essa situação não constitui uma regra. Pelo contrário: as situações que revelam a extrema dificuldade e o tormento moral próprio da individuação são aquelas em que a "voz interior" do Si mesmo entra em colisão com o código moral coletivo, a "lei moral geralmente aceita", constituindo um autêntico conflito ético.

Em um texto tardio, fundamental para a temática que estamos abordando, intitulado "Uma visão psicológica da consciência moral", Jung ([1958] 1970) estabelece uma distinção entre o código moral, que ele homologa ao superego freudiano, e a consciência moral ou moralidade como tal, que é homologada ao $\mathrm{Si}$ mesmo ${ }^{8}$. Ao passo que a consciência moral é um "atributo universal da psique humana, o mesmo não pode ser sustentado de um código moral” (Jung, [1958] 1970 [CW 10], \$ 833), que é portanto particular e, sendo histórico, inevitavelmente relativo. No espaço aberto por esta distinção, a possibilidade real do conflito ético é formulada com clareza: 
A consciência moral - não importa em que seja baseada - ordena ao indivíduo obedecer a sua voz interior, mesmo sob o risco de se extraviar. Podemos recusar obedecer a esta ordem apelando ao código moral e às visões morais nas quais ele se funda, embora com um sentimento desconfortável de termos sido desleais (Jung, [1958] 1970 [CW 10], \$ 841; grifos nossos).

Jung reiteradamente insiste na primazia da individuação como tarefa psicológica sobre as convenções de um código moral coletivo: “o código moral será, em certos casos, irremediavelmente abolido, e a decisão ética dependerá do indivíduo" (Jaffé, 1982: 285). Mas assevera que a boa solução para tais conflitos de dever entre a "voz interior" e a comunidade ética a que o indivíduo pertence supõe suportar o conflito até o fim, e sua natureza "está em acordo com as fundações mais profundas da personalidade assim como com sua totalidade; ela abarca consciente e inconsciente e por conseguinte transcende o ego" (Jung, [1958] 1970 [CW 10], \$ 856) 9 .

Porém é preciso insistir sobre o caráter doloroso do conflito ético e a dificuldade de sua solução: o eu consciente não consegue se eximir do mesmo de forma definitiva suprimindo um dos termos opostos, quer aderindo ao código moral vigente, quer adotando uma atitude infantil que consiste em descartar-se da responsabilidade da decisão entregando-se ao impulso provindo do inconsciente. Nas Memórias, após afirmar que não devemos sucumbir nem ao bem, nem ao mal, Jung diz: "Nada pode nos poupar do tormento da decisão ética" (Jaffé, 1982: $285)^{10}$. A sua perene insistência sobre a importância psicológica do problema do mal deveria nos alertar para isso. O impacto sobre a individuação que, como Jung insiste, se dá sempre no mundo é evidente:

Não é preciso muita imaginação para ver o que esse envolvimento nos caminhos do mundo significa no sentido moral. Só uma pessoa infantil pode pretender que o mal não está em ação por toda parte, e quanto mais inconsciente ela for, mais o diabo a comandará. [...] Somente o autoconhecimento implacável na escala mais ampla, que vê o bem e o mal em perspectiva correta e pode pesar os motivos da ação humana, oferece alguma garantia de que o resultado final não será muito ruim (Jung, [1951] 1968 [CW 9-ii], \$ 255; grifos nossos).

Portanto, Jung postula que o autoconhecimento é capaz de ver o bem e o mal em perspectiva correta. Eis uma afirmação problemática, que necessita ser temperada pela posição mais cautelosa de Jung - e também majoritariamente predominante -, como quando ele afirma que "na questão do bem e do mal, 
enquanto terapeuta pode-se apenas esperar que se esteja tomando os fatos de modo correto, embora não se possa nunca estar seguro" (Jung, [1959] 1970 [CW 10], \$ 866). Não fosse esse índice ineliminável de incerteza, a decisão ética não ofereceria tormento algum. É justamente pelo fato de a individuação se dar necessariamente no mundo, reino da contingência e da variabilidade, que a opacidade da situação prática é insuprimível, em maior ou menor grau.

$\mathrm{Na}$ vida e na praxis psicoterapêutica, o problema do bem e do mal será enfrentado empiricamente, o que significa que na "realização moral" não se pode recorrer a um acervo de normas éticas dadas a priori (nem mesmo aquelas que se poderia desentranhar em mitos e contos de fadas, tão estimados pelos junguianos). A singularidade da situação prática tem sempre precedência sobre a universalidade de normas éticas de conteúdo definido. Para Jung, não existem normas que sejam absolutamente ou incondicionalmente válidas:

A formulação de normas éticas não é apenas difícil mas na verdade impossível, porque dificilmente se pode pensar em uma única regra que não devesse ser também invertida sob certas condições. Inclusive a simples proposição "conscientizar é bom" só tem validade limitada, pois não raras vezes nós nos defrontamos com situaçôes em que a conscientização teria as piores consequências possíveis. Por isso estabeleci como regra tomar a "velha ética" ${ }^{11}$ como obrigatória apenas enquanto não houver evidência de seus efeitos prejudiciais. Mas se houver ameaça de consequências perigosas, estaremos diante de um problema de primeira ordem, cuja solução desafia toda a personalidade, exigindo o máximo de atenção, paciência e tempo. De acordo com a minha experiência, esta solução é sempre individual e apenas subjetivamente válida (Jung, [1949] 1980 [CW 18], $\$ 1413$; grifos nossos).

Porém, é necessário atentarmos para o fato de que, por baixo dessa variabilidade, há um critério normativo implicitamente assumido por Jung: "evitar as piores consequências", os "efeitos prejudiciais". Se o conteúdo concreto da efetivação dessa norma, vinculado ao julgamento moral correspondente, é relativo à circunstância, variável, e portanto particular, a normatividade moral em si mesma é universal:

A relatividade do "bem" e do "mal" não significa de forma alguma que essas categorias não sejam válidas ou não existam. O julgamento moral existe sempre e em toda parte, com suas consequências características. [...] São os conteúdos do julgamento que mudam, submetidos às condições de tempo e de lugar, e em consequência destes (Jaffé, 1982: 285). 
Por esse motivo, é inevitável a adoção de uma "atitude empírica", que leve em consideração, na conduta psicoterapêutica, o que os gregos antigos designavam como kairos, ou seja, o complexo de variáveis temporais, locais, relacionais e finais cambiantes e relativas que constituem a situação concreta como um todo. Contudo, Jung afirma expressamente que:

[...] adotar uma atitude empirica não significa que eu relativize o bem e o mal em si. Eu vejo muito claramente: isso é mau, mas o paradoxo é justamente que para esta pessoa em particular, nesta situação particular, neste estágio de desenvolvimento particular pode ser bom. Inversamente, o bem no momento errado, no lugar errado, pode ser a pior coisa possível. Se não fosse assim, tudo seria tão simples - simples demais (Jung, [1959] 1970 [CW 10], \$ 866).

Mas, devemos insistir, qual o fundamento que nos permite ajuizar sobre o que é bom e o que é mau para um indivíduo numa situação particular? Segundo a lição da ética filosófica, a inteligibilidade da praxis pressupõe a normatividade imanente do fim pelo qual ela se orienta (Vaz, 2000), o que significa que, em toda situação particular, a intenção de encontrar a melhor maneira possível de realização de um determinado fim revela-se como intenção de alcance universal. Aplicando este axioma ao nosso caso: se os caminhos da individuação são tortuosos, paradoxais, contingentes, a própria individuação, categoria que torna inteligivel a praxis psicoterapêutica junguiana, ao mesmo tempo apresenta-se como norma imanente e universal para a mesma.

Se refletirmos sobre os relatos fragmentários de intervençōes e atitudes clínicas de Jung, dispersos em suas obras, correspondência e nos testemunhos de quem conviveu e trabalhou com ele, veremos com facilidade que, na praxis psicoterapêutica, ele claramente orientava-se pelo critério da individuação ou realização do Si mesmo, que representava assim o critério universal que regia a consideração da relatividade inerente à situação prática. A incerteza sempre presente na avaliação da direção apontada pelo impulso de individuação, derivada da fragilidade cognitiva que não permite ao terapeuta uma segurança absoluta na abordagem dos fenômenos anímicos, não suprime a postulação de uma objetividade subjetiva do impulso de individuação como critério normativo.

Tal objetividade, supostamente, manifesta-se em "certas linhas do desenvolvimento psicológico, de natureza tanto individual como coletiva”, sobre as quais Jung afirma:

Não há conhecimento no mundo que possa provar a "certeza" dessas linhas; o racionalismo, pelo contrário, pode provar facilmente que elas não são certas. 
Seu valor, no entanto, é atestado pelo extremo valor vital dessas linhas. [...] O traçado vital hermeneuticamente construído é breve, uma vez que a vida não segue linhas retas, pressentidas num futuro distante. Diz Nietzsche que "toda verdade é sinuosa”. Os traçados de vida, portanto, nunca são princípios ou ideais válidos para todos, mas pontos de vista e posiçóes de validade efêmera. A baixa de intensidade vital, a perda sensível da libido, ou ainda uma impetuosidade excessiva indicam que o traçado foi abandonado e que se inicia, ou deveria iniciar-se, um novo (Jung, [1916] 1966 [CW 7], \$ 493-501).

Evidentemente, "desenvolvimento psíquico" remete ao processo de individuação, e as linhas vitais que o dirigem, com toda a sua "brevidade" e "sinuosidade", orientam-se para a realização do Si mesmo, fim último visado pelo impulso de individuação em seus "traçados de vida"12. Cabe à psicoterapia tentar "construir hermeneuticamente" esse traçado vital, que justamente só terá validade individual e subjetiva. É por isso que, em se tratando dessa "realização moral", "nenhuma teoria pode informar sobre as exigências últimas da individuação, nem existem à disposição receitas que [possam] ser usadas rotineiramente" (Jung, [1957] 1980 [CW 18], \$ 1172).

Estamos agora em condições de responder à pergunta levantada anteriormente. A análise não é uma forma de aconselhamento moral ${ }^{13}$. A sua dimensão ética significa a exigência de uma forma específica de compromisso moral por parte do sujeito com o conhecimento que se produz na sua experiência das imagens do inconsciente ${ }^{14}$. Porém esse compromisso já pressupõe a integridade prévia do "fator moral", por ser definido como "lealdade a si mesmo". Essa "realização moral" tem como princípio orientador não o Eu consciente, com seus desejos e temores, mas o Si mesmo. E aqui cabe lembrar que na experiência junguiana o impulso que comanda a individuação frequentemente trabalha contra os interesses vitais do indivíduo, do Eu consciente, expondo-o mesmo a riscos e perigos consideráveis (Jarret, 1988).

Por outro lado, é imperativo observar que o confronto entre Eu e Si mesmo tem necessariamente como pano de fundo a comunidade ética a que o sujeito solicitado pelo impulso de individuação pertence. Isso entranha duas consequências: a primeira é que o abandono - doloroso, para um sujeito ético - das diretrizes morais comunitárias não significa arbitrariedade ou anomia, mas sim o encontro de uma lei que Jung afirma ser mais severa do que qualquer outra lei: a lei que determina os contornos da própria individualidade (Jarret, 1988). A segunda que nada mais é do que a outra face da primeira - é que a anuência ao impulso de individuação, representando frequentemente uma transgressão ou uma ultrapas- 
sagem dos valores estabelecidos que regem a vida de uma comunidade ética ${ }^{15}$, impõe ao indivíduo a dolorosa experiência de sua própria solidão, consequência inevitável da ruptura da inconsciente adesão ao grupo social. Evidentemente, isso não significa o cancelamento da socialidade que define essencialmente o ser humano, mas a transformação da relação intersubjetiva para o indivíduo: acirra-se a necessidade agudamente sentida de comunicação em profundidade com o outro, e a construção dessa comunicação aparece como uma exigência constitutiva da própria individuação ${ }^{16}$. Jung reiteradamente insiste em que a individuação só pode se dar no mundo e não leva a um isolamento do sujeito, implicando sempre a interação intersubjetiva, a comunicação humana profunda. Mas ao mesmo tempo experimenta-se a insuficiência dessa comunicação para remediar a solidão mais abissal com que se depara o sujeito na experiência da individuação: assim abre-se o espaço para a compreensão do sentido humano profundo da experiência religiosa, enquanto experiência do "totalmente Outro".

Do que foi dito, percebe-se que a individuação, eixo-mestre da praxis junguiana, pressupõe a disponibilidade para o autossacrifício - o sacrifício do Eu em face das exigências do Si mesmo, o que implica também disponibilidade para suportar o sofrimento, pois é preciso lembrar que o tormento ético a que Jung se refere é constitutivo do "laborioso e muitas vezes penoso trabalho de educação ética" (Vaz, 2000: 73) que revela a dimensão fundamental do trabalho analítico/ psicoterapêutico. Apresentaçôes adocicadas e inocentes da psicologia de Jung esquecem-se dessa dimensão essencial, traindo o seu espírito profundo. Com o triunfo e as promessas da tecnologia, tornamo-nos cada vez mais intolerantes a qualquer desconforto, seja material, seja psicológico. Ora, se a terapêutica junguiana apresenta de partida as exigências da integridade do "fator moral" e da disposição a suportar o sofrimento (ambas em declínio em nossa civilização, sendo o hedonismo amoral apenas uma das faces mais comuns e banais com que o niilismo moderno ocupa o cenário social contemporâneo), então o destino de uma proposta psicoterapêutica como a formulada por Jung é incerto, e sua atualidade torna-se extremamente problemática.

$\mathrm{O}$ estranhamento com respeito às diretrizes impessoais que moldam o mundo, já acusado e sentido por Jung, é o preço a ser pago por quem não se inclinar a uma ou outra forma de aggiornamento de sua visão psicoterapêutica radical e insistir na "lealdade a si mesmo" como condição para a legítima realização de sua individualidade conforme a concepção própria da psicologia analítica. A possibilidade de individuação, de realização do Si-mesmo, de "encontrar a própria alma", condiciona-se nesse cenário à capacidade de ver no rosto do outro um enigma, sua absoluta inutilidade no que concerne à realização dos desejos pessoais e, por con- 
seguinte, à capacidade de suportar o fracasso, a dor, a solidão e, em boa medida, a falta de lugar. Contra essa possibilidade, o mundo oferece exatamente as ilimitadas vias de realização dos desejos, do aparente domínio sobre a própria existência, de instrumentalização da relação com o outro, para assim evitar o lado atormentado e doloroso da experiência da individuação. Nesse cenário, insistir na tentativa de individuação, com o pesado ônus que ela impõe, pode aparecer como nostálgica e rematada loucura. Mas é justamente a essencial dimensão ética da psicologia analítica que nos obriga a meditar sobre tal situação, para à luz dela pensar a (in)atualidade da praxis junguiana.

\section{REFERÊNCIAS BIBLIOGRÁFICAS}

Giegerich, W. (1999). Der Jungsche Begriff der Neurose. Frankfurt/M, Berlin, Bern, New York, Paris, Vienna: Peter Lang.

Hillman, J. (1984). The thought of the heart. Dallas: Spring Publications.

Jaffé, A. (ed.) (1982). C. G. Jung. Memórias, sonhos, reflexões. Rio de Janeiro: Nova Fronteira.

Jarret, J. L. (ed.) (1988). C. G. Jung. Nietzsche's Zarathustra. Notes of the Seminar given in 1934-1939. Princeton: Princeton University Press.

Jung, C. G. (1916/1966). The structure of the unconscious. The collected works of C. $G$. Jung. Volume 7: Two essays on analytical psychology. Princeton: Princeton University Press. . (1934/1969). Basic postulates of analytical psychology. The collected works of C. G. Jung. Volume 8: The structure and dynamics of the psyche. Princeton: Princeton University Press.

. (1935a/1966). The relations between the ego and the unconscious. The collected works of C. G. Jung. Volume 7: two essays on analytical psychology. Princeton: Princeton University Press.

. (1935b/1980). The Tavistock lectures. The collected works of C. G. Jung. Volume 18: The symbolic life. Princeton: Princeton University Press.

. (1946/1954). Analytical psychology and education. The collected works of $C$. G. Jung. Volume 17: The development of personality. Princeton: Princeton University Press.

. (1949/1980). Foreword to Neumann: Depth psychology and a new ethic. The collected works of C. G. Jung. Volume 18: The symbolic life. Princeton: Princeton University Press. 
(1951/1968). Aion. Researches into the phenomenology of the Self. The collected works of C. G. Jung. Volume 9-ii. Princeton: Princeton University Press.

. (1952/1969). Answer to Job. The collected works of C. G. Jung. Volume 11: Psychology and religion: west and east. Princeton: Princeton University Press.

. (1954/1968). Archetypes of the collective unconscious. The collected works of

C. G. Jung. Volume 9-i: The archetypes and the collective unconscious. Princeton: Princeton University Press.

. (1957/1980). Foreword to Michael Fordham: New developments in analytical psychology. The collected works of C. G. Jung. Volume 18: The symbolic life. Princeton: Princeton University Press.

. (1958/1970). A psychological view of conscience. The collected works of C. G. Jung. Volume 10: Civilization in transition. Princeton: Princeton University Press. . (1959/1970). Good and evil in analytical psychology. The collected works of C.

G. Jung. Volume 10: Civilization in transition. Princeton: Princeton University Press. Pieri, P. F. (2002). Dicionário junguiano. São Paulo: Paulus.

Vaz, H. C. L. (2000). Escritos de filosofia V. Introdução à ética filosófica 2. São Paulo: Loyola. Von Franz, M.-L. (1985). A sombra e o mal nos contos-de-fada. São Paulo: Paulinas.

\section{Notas}

1 No tocante às obras de Jung, utilizou-se a edição anglo-americana, até agora a de maior aceitação internacional, referência para pesquisa, apesar de seus problemas. As traduções são de nossa responsabilidade. Indicamos no texto, conforme o uso internacional, o volume entre colchetes e o parágrafo das citações, ao invés de citar as páginas - o que facilita a consulta a qualquer das traduções que adote o sistema internacional.

2 Cabe lembrar que em Jung a função sentimento é uma função racional e judicativa, isto é, produz juizos de valor, estando, portanto, vinculada a todo o âmbito moral. Assim, "violar os valores do sentimento" significa atentar contra a "atitude moral".

3 Isto é, como uma formação do inconsciente distinta das demais (anima, animus, Si mesmo, etc), e não como designando a totalidade do campo inconsciente, sentido amplo atribuído à sombra por Jung, conforme o testemunho de Marie-Louise von Franz (1985).

4 Para uma crítica das resistências de Jung aos apelos estetizantes da anima, veja-se Hillman (1984).

5 “[A] cura da neurose não é, em última análise, uma simples questão de habilidade terapêutica, mas uma realização moral” (Jung, [1957] 1980 [CW 18], \$ 1172).

6 "Aquele que não possui esta função moral, esta lealdade a si mesmo, nunca se livrará de sua 
neurose. Mas aquele que tenha esta capacidade certamente encontrará o modo de curar-se” (Jung, [1916] 1966 [CW 7], \$ 498).

7 Jung diz que as determinações inconscientes "só podem ser corrigidas através de compreensão consciente e determinação moral, e é por isso que o autoconhecimento, sendo tão necessário, é tão temido” (Jung, [1951] 1968 [CW 9-ii], \$253). Para ele, a superação do medo do inconsciente "é frequentemente uma realização moral de primeira grandeza" (Jung, [1951] 1968 [CW 9-ii], \$ 62).

8 Poderíamos assinalar aqui a afinidade da posição de Jung com o fragmento de Heráclito Ethos anthropoi daimon -, lembrando ainda a vinculação que Jung faz da "voz interior" ao daimon e, no texto sobre a consciência moral, entre o ethos e a "voz interior". Essa afinidade não é casual nem forçada: Jung afirmava claramente a semelhança entre o processo psicoterapêutico e a vida filosófica antiga. Assim, a individuação como "realização moral" pode ser entendida como uma versão da educação ética na filosofia antiga. Desenvolvemos esse ponto extensamente no livro Símbolo e sabedoria prática. C. G. Jung e o mal-estar da modernidade (São Paulo: Edições Loyola, 2008) e apresentamos o argumento, de forma abreviada, em “'It is something like antique philosophy': analytical psychology and philosophical practical Wisdom", in Spring Journal \# 77 - Psychology and Philosophy, New Orleans, spring/ 2007, pp. 69-88.

9 A referência implícita ao Si mesmo enquanto totalidade psíquica é aqui inconfundível.

10 "Quando se toca no mal, corre-se o risco de se sucumbir a ele. Ora, o homem, de um modo geral, não deve sucumbir nem mesmo ao bem. Um pretenso bem ao qual se sucumbe perde seu caráter moral, não porque tenha se tornado um mal em si, mas porque determina consequências más, simplesmente porque se sucumbiu a ele. Qualquer que seja a forma que revele o excesso a que nos entregamos, como o álcool, a morfina ou o idealismo, é nociva. Nunca devemos sucumbir à sedução daquilo que é prejudicial. [...] Nada pode poupar-nos do tormento da decisão ética" (Jaffé, 1982: 284-285).

${ }^{11}$ Esta passagem encontra-se no prefácio escrito em 1949 por Jung para uma versão inglesa do livro de Erich Neumann, Depth psychology and a new ethic. Jung considera essa "nova ética" (que Neumann afirma emergir da experiência contemporânea da psicologia das profundezas) "como um desenvolvimento e diferenciação dentro da ética antiga" (Jung, [1949] 1980 [CW 18 ], $\$ 1416$ ), e não como uma anulação simples da mesma. Por isso, a "velha ética" continua sendo relativamente válida, como a sequência da citação permite comprovar. Numa carta a Neumann de 13/06/1957, Jung afirma que expressaria o problema ético em termos diferentes dos que ele utilizara; para começar: não chamaria a ética enraizada na psicologia do inconsciente de "nova", justamente por ela ser tão-somente uma diferenciação no interior da ética "antiga", e assim termina por repudiar a expressão "nova ética".

12 "Qualquer que seja o significado da totalidade, do Si-mesmo do homem, empiricamente este 
Si-mesmo constitui uma imagem da finalidade da vida, produzida espontaneamente pelo inconsciente, para além dos desejos e temores da consciência. Representa a finalidade do homem total" (Jung, [1952] 1969 [CW 11], \$ 745).

13 "A questão [terapêutica] propõe-se do seguinte modo: o que, para este indivíduo, e neste dado momento, surge como um progresso à altura da vida? Isto não pode ser respondido por nenhuma ciência, por nenhuma sabedoria de vida, por nenhuma religião, por nenhum bom conselho, mas só pela consideração absolutamente sem preconceitos da semente de vida psicológica que se expande da cooperação natural do consciente e do inconsciente, por um lado, e do individual e coletivo, por outro” (Jung, [1916] 1966 [CW 7], \$ 488-489).

14 "Embora todo ato de conscientização seja no mínimo um passo adiante no caminho da individuação, ou seja, da 'totalização' do indivíduo, a integração da personalidade é inconcebível sem a relação responsável, ou seja, moral das partes entre si, assim como é impossível a constituição de um país sem a inter-relação de seus membros. Portanto, o problema ético se coloca por si, e é primariamente a tarefa do psicólogo encontrar uma resposta ou ajudar seu paciente a encontrá-la” (Jung, [1949] 1980 [CW 18], § 1412).

${ }^{15} \mathrm{O}$ conflito ético assim instaurado é visto por Jung segundo a imagem do pecado original (Jarret, 1988).

16 "Não devemos entender o indivíduo como voltado para dentro apenas sobre si mesmo; senão a individuação levaria ao completo desaparecimento do indivíduo são. Ele deve reaparecer de novo. [...] Não faz sentido voltar-se para dentro - desaparecer - se você não retornar com uma mensagem para as pessoas que estão fora” (Jarret, 1988: 668).

Recebido em 05 de setembro de 2008 Aceito para publicação em 04 de janeiro de 2009 